\title{
A formação médica e a clínica ampliada: resultados de uma experiência brasileira
}

\author{
The medical education and the extended general practice: \\ results of a Brazilian experiment
}

\author{
M aria de Lourdes $M$ armorato Botta H afner ${ }^{1}$ \\ $M$ agali A parecida Alves de $M$ oraes ${ }^{1}$ \\ M arilda $M$ arques Luciano $M$ arvulo ${ }^{1}$ \\ Luzmarina A parecida D oretto Braccialli ${ }^{1}$ \\ M ariaH elena Ribeiro de Carvalho ${ }^{1}$ \\ Romeu Gomes ${ }^{2}$
}

${ }^{1} N$ úcleo deAvaliação Institucional, Faculdadede M edicina de M arília. Avenida M onteCarmelo 800, Centro. 17519-030 Marília SP.

nucleodeavaliacao@famema.br

${ }^{2}$ Instituto Fernandes

Figueira, Fundação Oswaldo Cruz.
Abstract This is a qualitative study that is part of an evaluation research of a medicine course with the use of active teaching-learning methodologies based on thetriangulation of methods. The aim is to evaluate the results related to the extended general practice concept. The sources of information used in the study include 17 semistructured interviews with ex-prisoners and a situation that simulated the medical practice, of which seven ex-prisoners and a simulated patient participated. The analysis of the information and theproduction of thedata werebased on the method of interpretation of senses, according to the referential hermeneutic-dialectic system. The results point to aspects that justify the extended general practice, evidenced in two themes: the doctor-patient relationship and the patient approach. In conclusion, it is observed that the evaluated medical course brings together the education of the general, humanist, critical and reflexive doctor that may intervene in the different levels of health attention as well as in the individual and collective approach. It is also concluded that there are limits in operating an extended general practice in diverse health situations. Key words M edical education, Extended general practice, General practitioner, Qualitative evaluation research
Resumo Trata-se de um estudo qualitativo que faz parte deuma pesquisa deavaliação deum curso de medicina com o uso de metodologias ativas deensino-aprendizagem, baseada na triangulação de métodos. 0 objetivo é avaliar resultados relacionados ao conceito de clínica ampliada. As fontes de informação utilizadas no estudo abrangem dezessete entrevistas semi estruturadas com egressos e uma situação que simulava a prática médica, da qual participaram sete egressos e uma paciente simulada. A análise das informações e a produção dos dados baseiam-se no método de interpretação de sentidos, segundo referencial da hermenêuticadialética. O sresultadosapontam aspectosquefundamentam a clínica ampliada, evidenciados em duas temáticas: a relação médico- paciente eabordagem do paciente. Em termos de conclusão, observa- se que o curso de medicina avaliado se aproxima da formação do médico generalista, humanista, crítico e reflexivo, que pode intervir tanto nos diferentes níveis de atenção de saúde quanto no enfoque individual e coletivo. Conclui-se, ainda, quehá li mites para a efetivação de uma clínica ampliada nos diversos cenários de saúde. Palavras-chave Formação médica, Clínica ampliada, M édico-generalista, Pesquisa de avaliação qualitativa 
Introdução

As mudanças ocorridas no âmbito da formação médica - tanto em nível nacional quanto internacional - vêm refletindo princípios detransformações da educação e das políticas de saúde que procuram buscar novo referencial para a formação do profissional que a sociedade contemporânea exige. No Brasil, o movimento da Reforma Sanitária consolida, na Constituição Brasileira de 1988, a saúde como direito de todos e dever do Estado, abrindo espaço para a construção do Sistema Único de Saúde (SUS), o qual institui uma política de saúde que visa à integralidade, à universalidade, à busca da equidade, à incorporação de novas tecnologias, saberes e práticas.

A partir da década de noventa, em diversas escolas de medicina da América Latina, vêm sendo desenvolvidos novos modelos que utilizam como referência as necessidades sociais de saúde e procuram articular o ensino médico aos diferentes níveis de atenção à saúde ${ }^{1}$.

No início do século XXI, ocorre, no Brasil, a construção e a homologação das diretrizes curriculares para os cursos da área da saúde, visando desenvolver competências ehabilidades: atenção à saúde, tomada de decisão, comunicação, liderança, administração, gerenciamento e educação permanente ${ }^{2}$, na formação de um novo perfil de profissional de saúde para atuar no SUS.

Paratanto, os M inistérios da Saúdee da Educação aproximam-se, gerando ações conjuntas para reduzir a distância entre a universidade, os serviços de saúde e a comunidade 3 . As reformas dos cursos de medicina, sem dúvida, envolvem inúmeros desafios. Dentre eles, Campos ${ }^{4}$ destaca a necessidade de se reformarem saberes e práticas para reorientar tanto a clínica quanto a saúde pública. Caminhando nessa lógica, advoga que os cursos demedicina deveriam sevoltar para a formação de médicos capazes de resolver problemas de saúde, integrar-se em equipes multiprofissionais, reconhecer as determinações sociais, subjetivas e biológi cas da saúde/doença, elaborar planos terapêuticos articulados a essas determinações, construir vínculos e assumir responsabilidade em lidar com a cura e a reabilitação dos seus pacientes. Esse autor propõe a formação do profissional de medicina para a reformulação da clínica, tornando-a uma clínica ampliada, por meio da reorientação do campo de saberes, responsabilidades e práticas.

A clínica ampliada éenten dida, então, como a "transformação da atenção individual e coletiva, de forma que possibilite que outros aspectos do
Sujeito, que não apenas o biológico, possam ser compreendidos e trabalhados pel os profissionais"5. Os objetivos da clínica ampliada visam à produção de saúde nos distintos meios curativos, preventivos, de reabilitação ecuidados paliativos, como também à ampliação do grau de autonomia do usuário, família e da comunidade ${ }^{6,7}$.

Nessa perspectiva, a autonomia dos usuários seria ampliada a partir de ações que visam à promoção dos sujeitos, tornando-os mais capazes de compreender suas necessidades de saúde, entendendo seus agravos e participando como corresponsáveis no processo de produção de saúde ${ }^{6,7}$.

$\mathrm{N}$ as faculdades brasileiras de medicina, ligadas ou não à concepção de clínica ampliada, inúmeros movimentos vêm ocorrendo para promover mudanças curriculares. Dentre as iniciativas para essas mudanças, pode ser citada a Faculdade de M edicina de M arília (Famema), situada no interior do Estado de São Paulo, criada em 1966 e estadualizada em 1994, que tem assumido um papel relevanteno cenário nacional em relação à transformação da educação médica.

A Famema definiu, como missão institucional, a formação e a educação permanente de recursos humanos, integrando ensino, pesquisa e comunidade. Dessa forma, as ações institucionais vêm sendo reorientadas nosúltimos anos eincluem uma ampla revisão curricular, introduzindo metodologias ativas - como a aprendizagem baseada em problema (ABP) - e estabelecendo parceria com o Sistema M unicipal de Saúde.

A ABP é um método de ensino e aprendizagem centrado no estudante. Por esse método, o aluno adquire conhecimentos, habilidades e atitudes em situações que simulam a vida real. Tem como propósito formar estudantes capacitados a analisar problemas que enfrentarão na vida profissional. A característica inovadora da ABP é o uso de problemas como ponto de partida para aquisição de novos conhecimentos e a concepção do estudante como protagonista de sua aprendizagem ${ }^{8}$.

Ainda com base nas Diretrizes Curriculares Nacionais de 2001, a Famema tem como propósito formar um médico generalista, humanista, crítico, ético, capacitado a atuar no processo saúde-doença em seus diferentes níveis de atenção, com ações de promoção, prevenção, recuperação e reabilitação à saúde, na perspectiva da integralidade, com senso de responsabilidade social e compromisso com a cidadania 2 .

Pretende-se, além disso, que o médico formado pela Famema exerça no seu cotidiano a clínica ampliada, utilizando como estratégias de 
trabalho a integração da equipe multiprofissional, a delimitação de clientela, a construção de vínculo, a elaboração de projeto terapêutico conforme a necessidade de cada caso e a ampliação dos recursos de intervenção sobre o processo saúde-doença?.

A implantação do novo currícul o foi gradual einiciou-sepela primeira sérieem março de 1997. As unidades educacionais constituíram a célula básica do currículo, articulando as dimensões psicológica, biológica e social envolvidas numa situação ou problema de saúde. Para cada unidade educacional, foram definidos os objetivos deaprendizagem quepossibilitaram trabalhar os problemas em pequenos grupos de tutoria. Do currículo constavam, também, as unidades educacionais dehabilidades profissionais ea deinte ração comunitária, que propiciava a integração com a comunidade?.

Diversas análises sobre 0 desenvolvimento desse currículo possibilitaram a identificação de limites e potencialidades da organização curricular desenvolvida. Assim, foram definidas mudanças para propiciar maior articulação das dimensões biológica, psicológica e social, a integração teórico-prática e a qualidade da avaliação orientada à aprendizagem. A organização curricular, desde 2003, tem sido progressivamente voltada para o desenvolvimento do currículo por competência, entendida como capacidade de mobilizar articuladamente diferentes recursos psicomotores, afetivos e cognitivos, que permitam abordar e/ou resolver situações complexas referentes à prática profissional ${ }^{10}$.

Com base na experiência do curso demedicina da Famema, o presente artigo tem como objetivo analisar resultados relacionados ao conceito de clínica ampliada. Espera-se contribuir para o debate acerca de estratégias que envolvam metodologias ativas voltadas para a melhoria do ensino médico na atualidade.

\section{M etodologia}

0 presente estudo é parte de uma investigação quantitativa e qualitativa que procura avaliar os resultados do curso de medicina da Famema, considerado como um dos pioneiros na promoção da ABP como eixo da formação médica. Essa pesquisa foi aprovada pelo Comitê de Ética em Pesquisa da Famema, com base na Resolução $n^{\circ}$ 196/96 do Conselho Nacional de Saúde.

Neste artigo, focaliza-se a perspectiva qualitativa, aqui enten dida como um conjunto deprá- ticas interpretativas que busca investigar os sentidos que os sujeitos atribuem aos fenômenos e ao conjunto derelações em queeles se inserem ${ }^{11,12}$. N essa abordagem, com base em princípios da hermenêutica-dialética ${ }^{13}$, procura-se compreender e contextualizar os sentidos subjacentes às falas e às ações dos sujeitos investigados.

0 foco do presente estudo volta-se para os depoimentos fornecidos por egressos do curso em questão por meio de entrevista semiestruturada e pela participação desses em uma situação simulada. A partir da triangulação dessas técnicas, é possível estabelecer relações entre falas e ações para que se possam analisar os resultados da pesquisa em relação à clínica ampliada.

Pela entrevista semiestruturada aplicada a egressos (registrada por gravador de voz), a pesquisa enfoca os seguintes tópicos: a experiência do egresso em articular as dimensões biológica, psicológica e social, sua opinião sobre a relação mé dico-paciente e avaliação do curso da Famema.

No que se refere aos sujeitos entrevistados, levaram-se em consideração os seguintes princípios de amostra qualitativa: (a) escolha dos sujeitos que detêm os atributos relacionados ao que se pretende estudar; (b) consideração de tais sujeitos em número suficiente para que possa haver reincidência das informações; (c) consideração da possibilidade de inclusões sucessivas de sujeitos até que seja possível uma discussão densa das questões da pesquisa. Em vista disso, na constituição da amostra, não se buscou representatividade numérica e sim aprofundamento da temática ${ }^{14}$.

Com base nesses princípios, em relação às entrevistas realizadas pela pesquisa, foram selecionados egressos das turmas que tivessem finalizado o curso nos anos de 2003 e 2004 e estivessem atuando na rede pública de saúde e os que atuassem no serviço privado, no Estado de São Paulo e, ainda, os egressos que estivessem cursando a residência e os que não a cursavam. Dos egressos que participaram da pesquisa em geral, foram entrevistados dezessete, sendo sete do ano de 2003 (quatro do sexo masculino etrês do sexo feminino) e dez egressos de 2004 ( cinco do sexo masculino ecinco do sexo feminino). 0 foco nesse quantitativo, visto a partir de referências da aleatoriedade estatística, pode levar a um possível viés de análise. Entretanto, dentro de uma abordagem socioantropológica de pesquisa qualitativa, sem a pretensão de se trabalhar com a representatividade numérica, não há necessidade de abranger a totalidade de fal as e de expressões de um grupo estudado, uma vez quea dimensão 
sociocultural das opiniões e das representações grupais costuma expressar muitos pontos de vista comuns. Em vista disso, apesar de haver diversidade de opiniões e crenças dentro de um mesmo grupo, o espectro deopiniões eversões sobreuma dada realidade tem limites ${ }^{15}$.

Os egressos entrevistados foram convidados a participar de situações que simulavam a prática médica com uma paciente simulada ${ }^{16-21}$, num cenário estruturado da Famema. Na literatura, considera-seque os instrumentos utilizados para avaliação decompetência profissional são os testes de múltipla escolha, as estações com pacientes simulados e a observação direta da prática profissional22. Justifica-se, então, a opção de escolha da situação simulada no presente estudo.

D os dezessete en trevistados, sete egressos participaram efetivamente dessa atividade. Não houve uma reflexão acerca da recusa por parte dos outros dez egressos. A penas se respeitou a decisão de cada entrevistado sem questionar sobre isso. No entanto, algumas hipóteses explicativas para a não aceitação em participar da simulação podem ser levantadas. Uma possibilidade pode ser que os sujeitos nem sempre se sentem confortáveis em participar defilmagem, expondo sua imagem para fins analítico-interpretativos. Outra hipótese se refere ao fato de as gravações de mandarem certo tempo para a sua realização, exigindo que os sujeitos tivessem disponibilidade em suas agendas para as filmagens.

A situação simulada (que envolveu filmagem e registro em gravador de voz) referiu-se a um caso clínico fictício de uma usuária de um serviço público de saúde. 0 egresso foi escalado para substituir o médico titular. Na situação proposta, esse deveria informar à paciente, que retornava à consulta, o diagnóstico de tuberculose pulmonar bacilífera. 0 foco de observação foi à relação estabelecida pelo egresso com a paciente durante essa consulta.

Para garantir o sigilo, os egressos, tanto na entrevista quanto na situação simulada, foram identificados por nomes fictícios dados a cada participante, sendo representados com a inicial "A" egressos do ano de 2003 e "C" egressos do ano de 2004.

Para a análise dos dados, foram definidas duas categorias analíticas - que necessariamente não são excludentes - como foco para se analisarem as falas dos egressos gravadas nas entrevistas e suas ações na situação simulada. A primeira delas foi a relação médico-paciente, procurando nessa categoria verificar se havia uma tentativa do egresso em promover o encontro entre os sujeitos da clínica ampliada, o que cuida e o que é cuidado 5 , e se havia respeito à autonomia do paciente ${ }^{6}$. A segunda categoria foi a abordagem adotada pelo médico, observando-se se 0 egresso expressava um olhar ampliado para além da determinação puramente biológica ${ }^{4,6}$.

Em cada uma das categorias, procurou-se interpretar os sentidos que os egressos a elas atribuíam e se esses sentidos conseguiam ser "materializados" em suas ações durante a simulação.

Em relação à interpretação dos dados, o material selecionado foi trabalhado a partir do mé todo de interpretação de sentidos ${ }^{23,24}$. Esse mé todo baseia-se em princípios hermenêutico-dialéticos que buscam interpretar o contexto, as razões e as lógicas de falas, ações e inter-relações entregrupos e instituições.

$N$ a trajetória analítico-interpretativa dos depoimentos e das observações, foram percorridos os seguintes passos: (a) compreensão global do conjunto do material da pesquisa; (b) distribuição dos registros das entrevistas e das observações pelas categorias analíticas previamente definidas; (c) identificação e problematização das idéias explícitas eimplícitas nos materiais dentro de cada categoria analítica; (d) busca de sentidos mais amplos (socioculturais), subjacentes às falas e às ações dos sujeitos da pesquisa por categoria; (e) diálogo entre as idéias problematizadas e o referencial teórico do estudo e (f) elaboração de síntese interpretativa, procurando articular objetivo do estudo, base teórica adotada e dados empíricos.

\section{Resultados}

\section{A fala dos egressos}

No recorte das falas dos egressos, no quetangeà relação médico-paciente, observa-se que, em geral, esses apontam para o fato de que o curso contribuiu para uma boa relação médico-paciente. Dentre os argumentos que reforçam essa opinião, destacam-se as idéias de que o curso proporcionou uma "teoria direcionada para o doente" (Amaro) e uma "formação humanitária" (Alberto). Esses aspectos são vistos como importantes para o exercício da sua profissão, contribuindo para um atendimento e uma relação mé dico-paciente pautados em princípios éticos.

o primeiro sentido atribuído a uma boa relação médico-paciente pel os egressos éo de estabelecimento de vínculos. A exemplo disso, Alice, uma egressa, diz que é importante "estabelecer 
um vínculo com o paciente, porque o médico pode ter $100 \%$ de prática e de teoria, mas se não houver vínculo, ele não vai ter a adesão do paciente ao tratamento". Ainda em relação a isso, Cristiano, outro egresso, considera que uma boa relação com o paciente "abre uma possibilidade demelhorar o vínculo, facilitando as orientações quanto à modificação de estilo de vida, primeiro passo na terapêutica de doenças crônicas".

Outro sentido é o de saber ouvir e dar atenção. Dentro desse raciocínio, al guns egressos, como Cristian, consideram que é importante "primeiro entender como a paciente compreende seus problemas de saúde, qual valor dá para o que sente equal valor dá para a vida". Indo nessa mesma direção, Carmem argumenta que, quando o médico sabe escutar e presta a atenção ao que o paciente diz, ele faz "o diagnóstico para ganhar a confiança, o respeito, consegue discutir os aspectos do tratamento e fazer com que 0 paciente se trate". Prestar a atenção ao paciente, além do saber ouvir, também envolve a manifestação de alguns gestos e expressões. Como diz Alberto, na relação, "o cumprimentar, o dizer seu nome, o conversar, o olhar no olho do pacienteé o que vai fazer a diferença. É o que vai trazer respeito e confiança. E assim, essa troca torna-se positiva, principalmente quando o paciente percebe todo o empenho do médico para resolver aquele problema, mesmo que ele não o consiga".

Alguns dos entrevistados também atribuem a uma boa relação médico-paciente o sentido de seter respeito ao paciente. 0 depoimento deAline ilustra muito bem essa opinião: 0 paciente tem o direito de opinar sobre o tipo de tratamento que ele vai ter. Q uando sabe sobre seu diagnóstico e o que vai ser realizado, ele participa ativamente do seu tratamento.

Outro sentido atribuído à boa relação médico-pacienteéo depromover uma informação clara eacessível à compreensão do paciente. 0 depoimento de Amélia ilustra bem essa idéia: Primeiro explicaria, em palavras de fácil entendimento, sobre seus diagnósticos, pois, quando o paciente entende 0 que tem, fica mais fácil colaborar com 0 tratamento, seja medicamentoso ou não, ou ambos.

Também são apontados pelos egressos limites para se estabelecer uma boa relação médicopaciente. Amaro faz uma referência ao "meio [sistema de saúde] que obriga a distorcer essa relação". Assim, o atendimento nesse sistema por demanda espontânea cria o vício de ter que atender muitos pacientes no menor tempo possível. Ainda nesse raciocínio, considera-se que, mesmo com a formação quetiveram e reconhecendo que saíram preparados para prestar uma assistência humanizada, sentem-se pressionados a não agirem assim, pois, para esse mesmo egresso, "o médico ao lado não faz isso, então você destoa, você não consegue".

Possivelmente, o destoar para esse egresso se refere ao fato de, diante da precarização dealguns serviços públicos de saúde frente a demandas reprimidas, um profissional que dedica uma maior atenção a um usuário pode ser pressionado para atender a um número maior de casos, comprometendo assim a qualidade do atendimento.

$\mathrm{N}$ a fala dos egressos, também há referência à falta de respeito do médico para com o paciente do sistema público. Segundo Alberto, [Como o médico] ganha pouco por consulta, ele acha que não tem que atender bem eisso está errado, porque o médico está trabalhando lá porque quis; ninguém trabalha obrigado.

Essa fala pode apontar, pelo menos, dois sentidos a ela subjacentes. Um deles diz respeito às contradições entre o desejado e o vivenciado no cotidiano. Caminhando em outro sentido, podese concluir que o egresso deseja marcar uma diferença entre o queele faz eo queoutros médicos costumam fazer no âmbito do serviço público de saúde.

Em relação à abordagem adotada pelo médico, em geral, os egressos expressaram que o curso Ihes proporcionou uma abordagem adequada, entendida por eles a partir do sentido da integralidade. É recorrente a retomada de um dos princípios curriculares que advoga a articulação entreas dimensões biológica, psicológica esocial. A maioria reconhece que, na sua formação, foi possível uma compreensão do pacientede forma integrada, tratando todos os problemas, como expressa a fala de Camilo: Não só de saúde, mas ajudando na partesocial epsicológica equeajudou não só a metornar um profissional, masum médico de uma maneira um pouco mais completa.

Ainda que essa fala possa ser vista como uma ação fragmentada que reduz a ação em saúde à ótica biomédica, o egresso tenta caminhar na direção de ampliar sua ação para os âmbitos social e psicológico, entendendo que isso lhe favorece uma abordagem integral do paciente. Por outro lado, esse fragmento do depoimento também pode remeter a uma idéia de que - embora as instâncias psicossociais sejam deresponsabilidade de outros profissionais - cabe ao médico delas participar para que possa ter uma abordagem biomédica mais ampliada.

A integração biopsicossocial, segundo Alberto, passa a fazer sentido na vida profissional por- 
que "possibilita tratar o doente e não o exame, ser especialista do paciente, não da doença e tratar o paciente como se fosse al guém da própria família. Trata-se de um aprendizado que só foi possível nesse currículo".

A afirmação desse egresso não tem como ser comprovada em termos de um resultado efetivo do curso. Entretanto, o simples fato de - numa entrevista semiestruturada - ele recorrer livremente à idéia de se ampliar o olhar da doença para o paciente pode indicar que houve uma incorporação de idéias e princípios que nortearam a sua formação, ainda que no nível do discurso.

Os egressos, após sua formação profissional, percebem que as discussões sobre a integração biopsicossocial durante o curso foram importantes, tanto que essa se tornou espontânea na sua rotina, apesar das dificuldades encontradas no cotidiano da prática profissional.

Uma egressa, porém, aponta dificuldade de superar essa forma de abordar o paciente, devido à organização do sistema de saúde. 0 esforço de procurar "o máximo possível se policiar etentar fazer as coisas como elas devem ser feitas, independente de estar no SU S ou não", foi referido por Celina.

Consideram importante, em primeiro lugar, "se ater ao interesse do paciente enão do médico ou do sistema, pois somente desse modo o mé dico vai conseguir identificar as necessidades dentro das dimensões biopsicossociais", como se observa na fala de Antenor.

Admitem, pelosrelatos, queesseatendimento integrado não éfácil no SUS, mas expressam pre ocupação em superá-lo, conformeAntenor, "atendimento global abordando o biopsicossocial é muito difícil: o médico não tem tempo, as pessoas não estão preparadas e o sistema de saúde não tem estrutura. Só o tempo e a prática constante vão acabar trazendo uma experiência maior nesse sentido, mas mesmo com dificuldades, tentase ao máximo reconhecer limitações nessas três dimensões que estariam interferindo na conduta ou num tratamento e tentar saná-las".

\section{As ações na situação simulada}

$\mathrm{Na}$ observação da situação simulada, verifica-se que as ações dos egressos reforçam os dois resultados por eles apontados em suas entrevistas. $\mathrm{Na}$ relação com o paciente simulado, há coerência entre a fala e a expressão não verbal. 0 desenvolvimento das consultas se deu de forma contínua, com falas, silêncio, gestos e emoções, sem mecanicidade.
Ao iniciar a consulta, os egressos iam até à porta, chamavam a paciente pelo nome, cumprimentavam-na e solicitavam-Ihe que entrasse e sentasse. Em geral, apresentavam-sefalando seus nomes, explicando que estavam ali como substitutos e apenas um não se apresentou como tal. Durante os atendimentos, consideraram a autonomia da paciente: 0 queéimportanteérespeitar a sua vontade (Cristiano); Tudo bem em fazer 0 tratamento? (Antenor).

Considerar a autonomia do paciente pressupõe dar uma abertura para ele, acolhêlo, oferecer espaço para a fala e para o diálogo. É alterar esta relação de poder dominante na saúde, em que o profissional é elevado à protagonista e 0 usuário é constrangido a ser platéia. Respeitar a autonomia do paciente é contribuir com sua capacidade de enfrentar os problemas e ser ator na produção de sua saúde e de si.

Ainda que os egressos expressem a autonomia de uma forma simplificada, podemos identificar a tentativa de partilhar com o paciente, quando possível, decisões para que ele se torne sujeito do processo de cuidados. $\mathrm{Na}$ simulação com outro egresso, observamos que a autonomia se encontra mais qual ificada quando ele procura discutir com a paciente a necessidade de se realizar o exame de HIV, procedimento que demanda uma autorização do paciente.

Apenas um egresso alterou o tom de voz, mostrando-se mais impositivo: Se a senhora não me escutar e não acreditar em mim, aí não tem jeito, tem que acreditar em mim (Amaro).

Todos os egressos estabeleceram diálogo com a paciente, olhando nos olhos, alternando com a escrita, demonstrando interesse em ouvi-la. U tilizaram técnicas decomunicação paraverbal a fim de estimular a fala da paciente como, por exemplo, "entendi" e "tá", e confirmaram com a linguagem não verbal, como meneio de cabeça, a interação com a mesma.

Tranquilizaram a paciente diante dos seus sentimentos de preocupação. Exemplo disso se destaca na fala de Antenor durante a consulta simulada: Fique tranquila, nós vamos ver os resultados dos exames e eu vou orientar a senhora direitinho, para o que for melhor, no que a gente conseguir fazer, mas não fique assustada, é muita coisa acontecendo ao mesmo tempo.

Resgataram a compreensão da paciente sobre a doença, esclareceram conceitos, clarificaram a história da tuberculose, a gravidade da doença e a importância do tratamento, como expressa a pergunta feita por Cristiano: 0 que a senhora sabe da tuberculose? 
Ao comunicarem o diagnóstico para a paciente, mantiveram-se calmos diante do choro da mesma, mantendo fala tranquila e segura, respeitando o choro e com postura de ajuda. $\mathrm{Na}$ saída da paciente, todos se despedi ram com aperto de mão e afetividade.

No que se refere à abordagem do paciente, realizaram o exame físico, respeitando a privacidade, segurança e conforto da paciente, bem como o direito à informação. No conjunto dos egressos, apenas um não realizou o exame físico. Em geral, os que o fizeram, pediram licença para iniciá-lo, para tirar ou levantar a blusa da paciente, para desabotoar a calça e examinar 0 abdome. Comunicaram o resultado da aferição da pressão arterial e ofereceram a escadinha para a paciente subir na maca.

Compreenderam ostemores da pacienteeajudaram-na alidar com os mesmos, como se observa na fala de Aline: Eu enten do quevocêfique realmente preocupada, qualquer pessoa ficaria preocupada, tanto quanto você, mas não precisa ficar pensando que eles vão te discriminar, quem discrimina é porque não conhece. Então a gente vai orientar.

Essa fala, embora possa ser interpretada como a negação da discriminação, caminha na direção de que se deve promover a informação para que sereduzam possíveis preconceitos frentea determinadas doenças.

Perceberam que a paciente estava se sentindo responsável por ter adquirido a doença e apresentaram falas de alívio e conforto, como exemplificado na fala de Alberto: Tuberculose a gente não pega porquequer. É diferentefalar detuberculosee deuma DST, por exemplo, uma doença transmitida pelo sexo. Então mais um motivo para você não ter vergonha e nem ficar de cabeça baixa.

Esse discurso, embora tenha sido expresso com a intenção de acalmar a culpa da paciente, não conseguiu de todo acabar com a culpabilização das pessoas por ficarem doentes, em casos que envolvem questões morais. Esse fragmento dedepoimento também serve para se discutir que o profissional de saúde não está imune ao senso comum, em queseestigmatizam doenças relacionadas à sexualidade.

Enquanto a paciente simulada abordou as questões de relacionamento interpessoal com 0 namorado, a maioria dos egressos se mostrou atenta, interessada em compreender o que a pacienteverbalizava, a exemplo da fala de Antenor: Procure conversar abertamente com ele, tanto dos seus receios, dos seus medos. Talvez a angústia se resolva a partir do momento em que você for sincera e ele também.
Apenas Amaro tentou, com frequência, retornar ao aspecto da doença e referiu: Depois a gente vê $o$ que pode fazer por ele. Bem, deixe-me examinar você.

Colocaram-se à disposição para conversar com outras pessoas diretamente relacionadas com a paciente: Eu me proponho a explicar para sua patroa, se a senhora quiser, a gente marca um dia, ela vem aqui ea gente explica o queétuberculose, como demonstra Celina e N ão precisa ficar desesperada, que eu posso explicar isso para seus pais, se você quiser, para seu namorado, se você quiser, até para a sua patroa, na fala de Cristiano.

Esses profissionais não ficaram restritos apenas à doença da paciente, mas olharam para a inserção da mesma em relação ao seu trabalho e à vida familiar. Preocuparam-se com a pessoa no foco da doença, mas também propiciaram abertura para a paciente colocar suas ansiedades, preocupações, temores e medos, valorizando não apenas 0 aspecto biológico, mas também o psicológico e social: Então você está com esse medo. Eu imagino como deve estar sendo difícil para você, por tudo isso que você está me contando, eu vejo que você está arrasada (Cristiano); A senhora trabalha com cartei ra registrada? Então a senhora tem direito de continuar no trabalho e se sua patroa estiver esclarecida, estiver a par do que está acontecendo, não vai ter motivo para ter esse tipo de preocupação. Eu estou te dizendo, eu me coloco à disposição para conversar (Antenor).

Em síntese, em termos de abordagem do paciente, os egressos não deixam de valorizar a seriedade da doença; contudo, procuram amenizar o sofrimento da paciente, falando sobre cura, a preservação do emprego edo namoro, dispondo-se a conversar com a patroa, a família e 0 namorado.

Durante as ações simuladas dos egressos, observa-se também que eles ampliam o olhar do atendimento aos comunicantes, quanto às medidas de prevenção e promoção à saúde, adesão ao tratamento e apoio da equipe multiprofissional, abordando a dimensão coletiva e não apenas a individual. As falas que seguem ilustram muito bem esse cuidado ampliado:

Essas pessoas têm que ter 0 conhecimento daquilo que a senhora tem, o que significa, quais os riscos. (Antenor)

A senhora ainda está transmitindo a bactéria. Então, as pessoas que ficam mais em contato com as pessoas com tuberculose, a gente precisa examiná-las, radiografá-las. (Celina)

Então a gente combina que amanhã cedo vai com a equipe aqui do posto lá na sua casa, vai 
orientar todas as pessoas, vai orientar sobre os exames que precisa fazer. (Aline)

Faz o tratamento durante quinze dias, e eu vou afastar a senhora, e vai ficar em casa, come çando a tomar o remédi o. Tomando o remédio, em quinze dias, D ona M aria, acabou a chance de passar para outra pessoa. (Carla)

Articulando a fala e a ação na situação simulada

Ao se comparar a fala dos egressos, expressas durante a entrevista, e as suas ações, realizadas na situação simulada, pode-se identificar a incorporação de princípios de uma clínica ampliada por parte deles. Como visto, isso se evidencia, principalmente, pela valorização da relação médico-paciente, o respeito pelo sujeito, tanto do ponto de vista biológico, psicológico e social, como de sua autonomia e nas ações curativas, preventivas e de reabilitação.

Em geral, há coerência entre o que, teoricamente, os egressos defendem por seus depoimentos, durante a realização da entrevista, e o que demonstram durante a situação simulada.

Olhando para as falas e ações dos egressos, com a lente da "clínica ampliada", observamos que eles se aproximam desse modelo de atenção.

As relações estabel ecidas entre os egressos ea paciente simulada revelam aspectos que fundamentam a clínica ampliada. 0 primeiro deles se refere ao foco da singularidade do paciente imprimido pelo ol har dos egressos. 0 paciente foi visto a partir de sua individualidade, sem que ficasse reduzido apenas a um exemplar de uma doença. Esse olhar ampliado também conseguiu deslocar-se do sujeito para as relações familiares desse e para possíveis inser ções em redes sociais. Outro aspecto que se faz notar nessa relação é o estabelecimento de vínculo. Tal vínculo tanto pode decorrer do ol har centrado na singularidade do sujeito da clínica como podeser entendido como condição para que tal singularidade seja reconhecida. Esses aspectos nos remetem ao que autores denominam de clínica ampliada25-27.

Ao considerar a singularidade do sujeito da clínica e ao estabelecer vínculos com essesujeito, com base em Tesser ${ }^{28}$, observa-se que os egressos dão voz ao paciente, por meio da escuta, fazendo da fala não só uma referência para seu diagnóstico eprognóstico, mas também situando-a como um dos componentes de uma relação dialógica. Essa relação, por sua vez, além de caminhar na troca de informações e no esclarecimento de dúvidas, com linguagem adequada, configura-se no acol himento de preocupações emedos ena abertura para que a ocorrência de novos encontros seja possível.

Assim, tomando como referência as idéias de Caprara eFranco ${ }^{25}$, podemos considerar que, em geral, nas atividades simuladas, a relação empática, participativa e comunicacional revela a capacidade de os médicos formados pela Famema ensaiarem uma clínica ampliada.

Por outro lado, nesse ensaio de transformar a atenção individual e coletiva num movimento de articulação entre as dimensões biológica, social e subjetiva, os limites para se ampliar a clínica não estão detodo ausentes. N esse sentido, tanto as falas quanto as ações dos egressos apontam limites, tais como a grande demanda a ser atendida num tempo curto, a pressão por parte dese reproduzir um modelo puramente biologicista, a ausência de uma equipemultiprofissional que possa dar suporte ao atendimento das necessidades de saúdee a dificuldade de se estabelecer um sistema de referência e contrarreferência.

\section{Consideraçõesfinais}

O estudo nos possibilita verificar que esses egressos estão se aproximando do médico generalista, humanista, crítico e reflexivo que pode intervir tanto nos diferentes níveis de aten ção de saúde, quanto no enfoque individual e coletivo. Porém, ainda que se mude a formação do médico e isso contribua muito, essa mudança não é suficiente para a efetivação de uma clínica ampliada nos diversos cenários de saúde. Além das Políticas de Saúde, como a HumanizaSUS, se faz necessária a reorganização no Sistema de Saúde para que se propiciem espaços de reflexão dos profissionais sobre sua prática e a da equipe. A educação permanente, no cenário da prática profissional, poderáser uma ferramenta fundamental para contribuir na transformação das práticas e dos sujeitos inseridos no SUS. Compreendemos que as pessoas precisam ser transformadas na sua prática cotidiana e isto só é possível por uma disponibilidadeinterna e deespaços de reflexão e colaboração entre as pessoas. Outro aspecto destacado é o de que precisamos investir também, durante o curso de medicina, na educação em saúde dos nossos usuários ou pacientes, porque, culturalmente, esses já esperam médicos que os atendam rapidamente, que peçam exames e os mediquem. Dessa forma, passivamente, esperam ser curados em vez de se curarem. Essa educação, por sua vez, não deve ser vista apressada- 
mente como um programa centrado na transmissão pura e simplesmente, por meio do ato de depositar, transferir e transmitir valores e conhecimentos, visando à modelagem de formas de pensar, sentir e agir. D eve ser concebida, a partir da perspectiva dialógica de Paulo Freire ${ }^{29}$, como o usuário do serviço de saúde ser reconhecido como sujeito portador de um saber que pode ser base para uma prática emancipatória de ressignificação do processo saúde-doença-cuidado ${ }^{30}$.

Além disso, faz-se necessária a mudança na lógica da medicalização que impera no sistema de saúde ocidental, reconhecendo-se que os saberes da biomedicina são profundamenteinsuficientes e, às vezes, danosos. É necessário reconhecer que os sujeitos da clínica (cuidadores e cuidados) são possuidores de subjetividades que podem influenciar mutuamente nos encontros. Essas devem ser reconhecidas e trabalhadas.

A valorização do saber generalista e humanista contribui para a ampliação da clínica, fazendo com que esta seja centrada em um atendimento integral, com vínculo efetivo, dando início a um novo patamar de diálogo, centrado não apenas na doença, mas na situação do doente, no seu sofrimento e nas suas condições psicossocioexistenciais.

\section{Colaboradores}

M LM B Hafner, M AA Moraes, M ML Marvulo, LAD Braccialli e M H R Carvalho participaram da coleta de dados, análise, discussão e redação do presente artigo e R Gomes participou da análise, discussão, redação e foi responsável pela orientação teórico-metodológica e bibliográfica do trabalho.

\section{Agradecimentos}

Aos egressos das turmas de M edicina da Famema dos anos 2003 e 2004 pela participação na pesquisa. Às bibliotecárias pela revisão bibliográfica, às secretárias do Grupo de Avaliação pelo apoio na formatação e à Famema pelo apoio financeiro. 
Referências

1. Cyrino EG, Rizzato ABP. Contribuição à mudança curricular na graduação da Faculdade de M edicina de Botucatu. Rev. Bras. Saude M atern. Infant. 2004; 4(1):59-60.

2. Brasil. Ministério da Educação. Conselho Nacional de Educação. Parecer CNE/CES 1.133/2001, de 07 de agosto de 2001. Diretrizes curriculares nacionais dos cursos de graduação em enfermagem, medicina e nutrição. Diário Oficial da União 2001; 3 out.

3. Lampert JB. Avaliação do processo de mudança na formação médica. In: M arins JJN, Rego S, Lampert JB, Araújo JGC, organizadores. Educação médica em transformação: instrumentos para a construção de novas realidades. São Paulo: Hucitec; 2004. p. 245-266.

4. Campos GWS. Educação médica, hospitais universitários e o Sistema Único de Saúde. Cad Saude Publica 1999; 15(1):187-193.

5. Cunha GT. A construção da clínica ampliada na atenção básica. São Paulo: Hucitec; 2005.

6. Campos GWS, Amaral MA. A clínica ampliada e compartilhada, a gestão democrática e redes de atenção como referenciais teórico-operacionais para a reforma do hospital. Cien Saude Colet 2007; 12(4):849-859.

7. Brasil. Ministério da Saúde. Secretaria de Atenção à Saúde. Núcleo Técnico da Política Nacional de Humanização. HumanizaSUS: documento base para gestores e trabalhadores do SUS. 3a ed. Brasília: Ministério da Saúde; 2006.

8. Bernabeu MD, Cònsul Giribet M. Aprendizaje basado en problemas. In: Cònsul Giribet $M$, coordinador. Historia de un cambio: un currículum integrado con el aprendizaje basado en problemas. BarceIona: Escola Universitària d’Infermeria Vall d'Hebron; 2007. p. 35-47.

9. Faculdade de Medicina de Marília. Manual FAMEM A 1999. M arília: Faculdade de M edicina de Marília; 1999.

10. Faculdade de M edicina de M arília. M anual de avaliação do estudante: Cursos de M edicina e Enfermagem. M arília: Faculdade de M edicina de M arília; 2006.

11. Denzin NK, Lincoln YS. Introduction: the discipline and practice of qualitative research. In: Denzin NK, Lincoln YS, editors. Handbook of qualitative research. Thousand Oaks: Sage; 2000. p. 1-29.

12. Deslandes SF, Gomes R. A pesquisa qualitativa em serviços de saúde: notas teóricas. In: Bosi MLM, Mercado FJ, organizadores. Pesquisa qualitativa de serviços de saúde. Petrópolis: Vozes; 2004. p. 99-120.

13. M inayo M CS. Hermenêutica-dialética como caminho do pensamento social. In: M inayo MCS, Deslandes SF, organizadoras. Caminhos do pensamento: epistemologia e método. Rio de Janeiro: Fiocruz; 2002. p. 83-107.

14. M inayo MCS. 0 desafio do conhecimento: pesquisa qualitativa em saúde. 9a ed. São Paulo: Hucitec; Rio de Janeiro: Abrasco; 2006.

15. Gaskell G. Entrevistas individuais e grupais. In: Bauer M, Gaskell G, organizadores. Pesquisa qualitativa com texto, imagem e som: um manual prático. Petrópolis: Vozes; 2000. p. 64-89.

16. Barrows HS. An overview of the uses of standardized patients for teaching and evaluating clinical skills. Acad M ed 1993; 68(6):443-451.
17. Troncon LEA, Foss NT, Voltarelli JC, Dantas RO. Avaliação de habilidades clínicas por exame objetivo estruturado por estações, com emprego de pacientes padronizados: uma aplicação no Brasil (parte II). Rev Bras Educ M ed 1996; 20(2-3):53-60.

18. Venturelli J. Recursos educacionales. In: Venturelli J. Educación médica: nuevos enfoques, metas y métodos. Washington, D.C.: OPAS; 1997. p. 193-205.

19. Howley LD. Performance assessment in medical education: where we've been and where we're going. Eval Health Prof 2005; 27(3):285-303.

20. Mazzoni CJ, M oraes MAA. A avaliação prática estruturada de habilidades clínicas na Famema: fundamentos para construção e aplicação. Gestão U niv [periódico na Internet] 2006 [acessado 2006 set 13]. Disponível em: http://www.gestaouniversitaria. com.br/scripts/print_mural.php?id=752\&print=y

21. Troncon LEA. Utilização de pacientes simulados no ensino e na avaliação de habilidades clínicas. M edicina (Ribeirão Preto) 2007; 40(2):180-191.

22. Epstein RM, Hundert EM. Defining and assessing professional competence. JAM A 2002; 287(2):226235.

23. Gomes R, Souza ER, M inayo MCS, M alaquias JV, Silva CFR. Organização, processamento, análise e interpretação de dados: o desafio da triangulação. In: M inayo M CS, Assis SG, Souza ER, organizadores. Avaliação por triangulação de métodos: abordagem de programas sociais. Rio de Janeiro: Fiocruz; 2005. p. 185-221.

24. Gomes R. Análise e interpretação de dados de pesquisa qualitativa. In: M inayo MCS, organizadora. Pesquisa social: teoria, método e criatividade. 25a ed. Petrópolis: Vozes; 2007. p. 79-108.

25. Caprara A, Franco ALS. A relação paciente-médico: para uma humanização da prática médica. Cad Saude Publica 1999; 15(3):647-654.

26. Caprara A, Rodrigues J. A relação assimétrica médico-paciente: repensando o vínculo terapêutico. Cien Saude Colet 2004; 9(1):139-146.

27. Campos GWS. El filo de la navaja de la función filtro: reflexiones sobre la función clínica en el Sistema Ú nico de Salud en Brasil. Rev. bras. epidemiol. 2005; 8(4):477-483.

28. Tesser CD. Medicalização social (II): limites biomédicos e propostas para a clínica na atenção básica. Interface (Botucatu) 2006; 10(20):347-362.

29. Freire P. Pedagogia do oprimido. 17ạ ed. Rio de Janeiro: Paz e Terra; 1987.

30. Alves VS. Um modelo de educação em saúde para o Programa Saúde da Família: pela integralidade da atenção e reorientação do modelo assistencial. Interface (Botucatu) 2004; 9(16):39-52.

Artigo apresentado em 05/12/2007

Aprovado em 04/06/2008

Versão final apresentada em 06/08/2008 